\title{
Review of the effect of sand on the behavior of expansive clayey soils
}

\author{
A. N. Alnmr ${ }^{1, *}$, R. P. Ray $^{1}$ \\ ${ }^{1}$ Széchenyi István University, Department of Structural and Geotechnical \\ Engineering, Egyetem tér 1, 9026 Győr, Hungary \\ "e-mail: ammar888999@ hotmail.com
}

Submitted: 19/04/2021; Accepted: 02/05/2021; Published online: 13/05/2021

Abstract: Clayey soils often showed undesirable engineering behavior such as low bearing capacity, swelling and shrinkage characteristics. However, chemical improvement, thermal improvement and improvement by additives like lime, cement and sand offer an efficient technique to overcome the problems resulting from Expansive soils. This paper presents a review of the swelling behavior of sand-clay mixtures as well as the effect of sand on the physical and mechanical characteristics of expansive soils. Results highlight the importance of sand in improving the behavior of expansive soils. Finally, the most important general conclusions about the behavior of expansive soils and suggestions for future researches are highlighted.

Keywords: expansive soils; additive material; sand-clay mixtures; mechanical characteristics; physical properties

\section{Introduction}

Expansive clayey soils spread over large areas of land within the world. The total value losses resulting from the destruction of structures built on expansive soils are estimated to be several billions of dollars worldwide so expansive soils are considered a high-cost problem when establishing structures on them. For example, the annual estimated loss of roads, buildings, airports and other structures in China, Britain and America exceeds $\$ 1$ billion, $£ 150$ million and $\$ 15$ billion, respectively [1] [2] [3] [4]. According to Nelson and Miller [5] the financial loss resulting from the devastating effects of expansive soils would be greater than the loss caused by earthquakes or floods. 
Besides, clayey soils cover 630 thousand hectares, which is approximately 6-9\% of Hungary's land, and another 1.7 million hectares are covered with clayey loamy soils. Its significant expanse and unique properties led to early scientific recognition in Hungary as well, and thus expansive soils can be found within the Hungarian soil science literature from its inception, from József Szabó's scientific work [6].

The foundation soil layer plays an important role in creating safe and cost-effective constructions. In case the site is unsuitable or the engineering works in which backfill plays an essential role, such as dams, roads and railways, requires large quantities of soil of certain specifications and bringing them to the site from long distances may be uneconomical, which call for improving the behavior of site soil itself.

There are many ways to improve the expansive soil behavior and choose between them depends on economic, practical and environmental standards. Common methods are chemical improvement, thermal improvement and improvement by additives such as lime, cement and sand.

Many researchers have conducted many laboratory and field experiments that confirmed that expansive soils with certain additives of other materials such as sand, silt, lime, fly ash, etc. can improve their behavior and used efficiently in the above engineering works[7] [8] [9].

Sand is a natural granular material and due to its high bearing capacity, it can be used as a filler material to improve the behavior of expansive soils. Therefore, sand can be used in various percentages by mixing it with expansive soil and thus altering the properties of plasticity, compaction, strength and permeability (Hydraulic conductivity, k) of mixtures [8] [9] [10] [11]. It is also well known that expansive soils comprise of different proportions of coarse fractions, which vary as function of soil, and therefore, studying the effect of sand on the behavior of the expansive soil has a high degree of importance.

\section{Literature review}

The swelling properties of expansive soils are due to several factors related to the initial soil conditions such as initial dry density and initial moisture content, the granularity and the content of clay so many correlations have been suggested depending on them for prediction of swelling potential in addition to various index properties such as liquid limit, plasticity index, shrinkage index, activity etc. However, the first factor that conditions swelling of expansive soil and affects these physical, chemical and mechanical properties is the mineralogical composition and the amount and type of minerals present in expansive soil. It is known for instance, that the phenomenon of swelling depends not only on the content of clay but also on 
the surface activity of the clay itself which will be more intense as the specific area of the particles will be high [12].

At the beginning, it is necessary to understand the process and behavior of swelling to enable us to interpret the results related to the effect of sand on the behavior of expansive soils. Then, the effect of sand on the most important parameters affecting the behavior of expansive soils will be reviewed.

\subsection{Swelling process}

The swelling-pressure behavior of expansive soil are often described in three steps: before, during, and after absorption of the water.

Fig. 1 shows the three steps. In the first step, expansive soil is formed of a mix of swelling clay minerals (such as montmorillonite), void, other non-swelling minerals and sand particles. Through this step, air and free water occupy the voids [13].

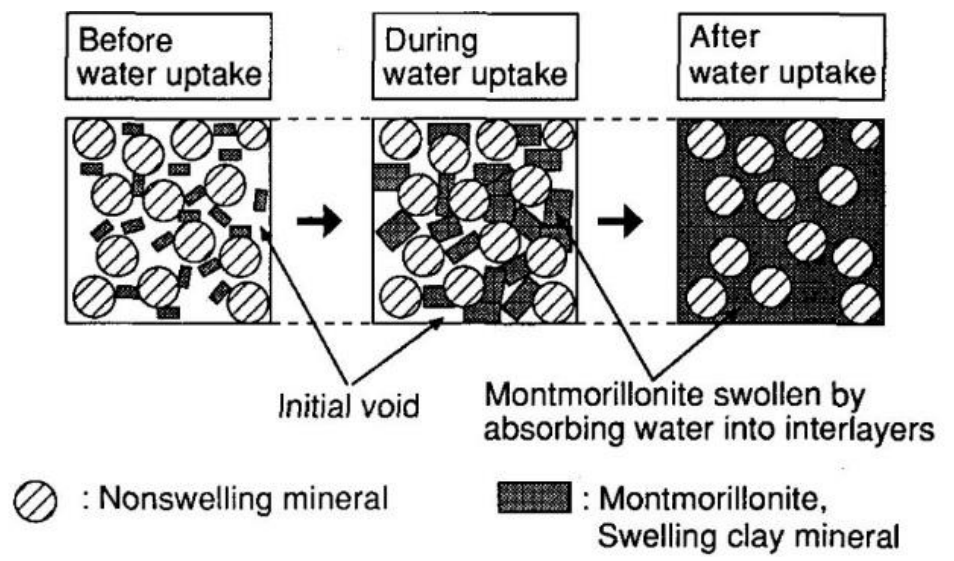

Figure 1. Mechanism on the swelling pressure of expansive soil from [13]

During water absorption, swelling clay mineral adsorbs water into interlayers and swells and occupies the void in the expansive soil. Therefore, expansive soil increases in size and swelling pressure occurs. Anyway, the interlayer and double layer forces are liable for the swelling behavior of the bentonite.

Finally, after the water is totally absorbed, and therefore the entire voids are filled with water, the volume of expansive soil cannot increase further. then, the swell pressure of the expansive soil can be measured 


\subsection{Swelling behavior}

The mechanism of the swelling has been extensively discussed in the literature [14] [15] [16] [17]. The swelling behavior of sand-clay mixtures is caused by two mechanisms known as crystalline swelling that relates to the degree of hydration and osmotic swelling is related to the cation in the interlayers. Also, the relative humidity plays major role in the swelling behavior.

\subsubsection{Crystalline swelling}

Crystalline swelling is that the first mechanism that occurs when montmorillonite absorbs water, that is, it is an outcome of short-term hydration. This mechanism results in an increase in the space between the interlayers of swelling minerals such as montmorillonite. As a result, an increase in the volume of the expansive soil is gained and as a result, the swelling pressure appears. Crystalline swelling is mainly caused by the energy related to the initial hydration of interchangeable interlayer cations and hydrogen bonds or the effects of charged surface dipole attraction associated with the solid-liquid interactions that occur in the immediate vicinity of the clay particle surfaces [15] [16]. Fig. 2 shows the conceptual model of the sequential crystalline swelling process of montmorillonite.

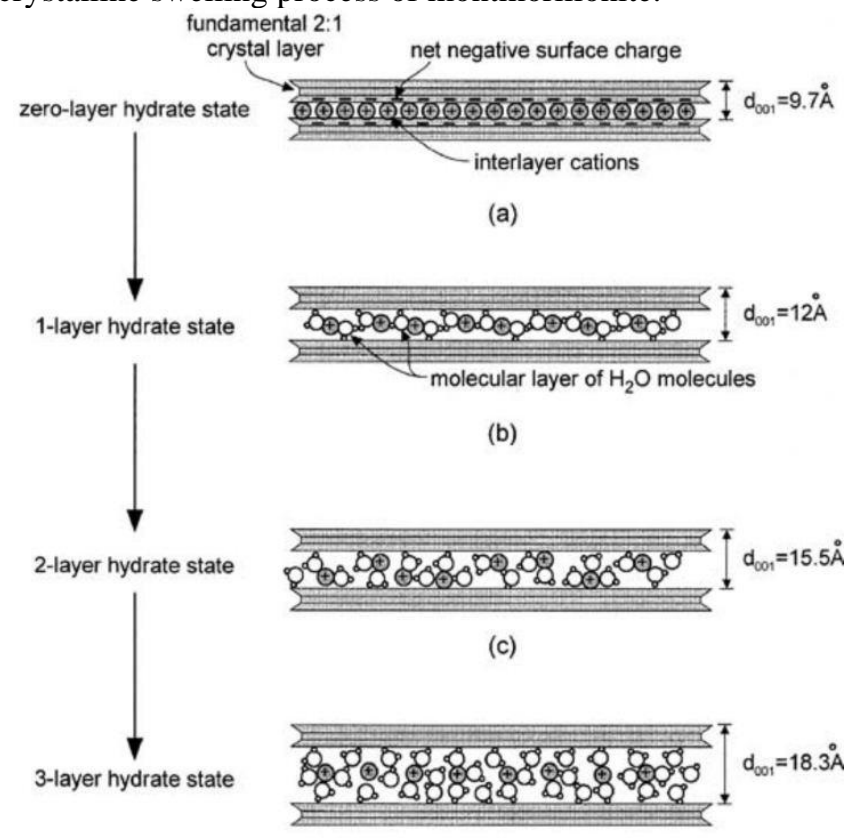

(d)

Figure 2. Mechanism of crystalline swelling of montmorillonite [16] 
It has not been confirmed but it is first supposed that the surface of the clay is completely enveloped with a layer of water molecules. Then the second molecular layer is covered and so on. In sum, the water molecules are distributed layer by layer. For sodium montmorillonite, the water molecules are enveloped from zero to four layers [18]. And according to foster [12] the cation of clay play an important role in The dissociation where the important relationship between clay composition and swelling is very satisfactorily explained by the concept of cation dissociation. When calcium is the accompanying cations, the degree of dissociation is not large enough to cause a significant degree of swelling; Whereas when sodium is the predominant bound cation, the degree of dissociation is much greater and sodium montmorillonite has swelling properties.

As shown in Fig.3, during the absorption of water, the negative dipoles of the water molecules are oriented towards the cation. Consequently, the electrostatic interaction between the layers and the interlayer cations decreases [15].

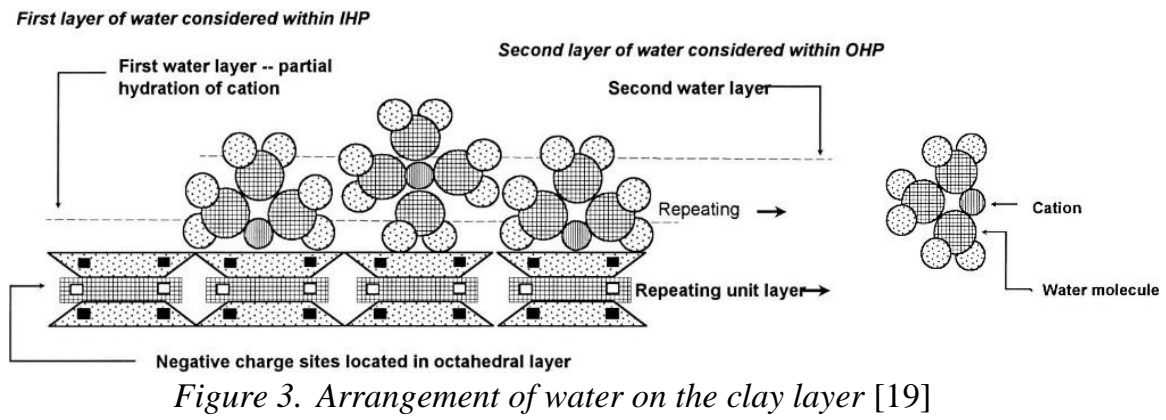

The outcome is an increment in the space between the layers of swell clay minerals and an increase in the volume of it. The swelling process can absolutely arrive at a separation of the layers because of the forces that developed as a result of absorbing water. In addition, if there are organic compounds, the distance between layers of montmorillonite can be diminished since the organic compound makes the surface hydrophobic [15] [16].

\subsubsection{Osmotic swelling}

Osmotic swelling is the second mechanism resulting from the adsorption of water by swelling clay minerals. This mechanism creates a persistently increasing distance between layers of the swelling clay mineral. The difference in concentration between ions near the surface of swelling clay mineral layers and in the porous water is the main cause of osmotic swelling. This mechanism is resulted in because of diffuse multiple-layer interactions and van der Waals gravity. 
Swelling clay mineral comprises of a lattice of $\mathrm{Al}_{2} \mathrm{O}_{3}$ and $\mathrm{SiO}_{2}$ units; A net negative charge creates on the clay surface when divalent minerals, for example, magnesium are substitute in the lattice for aluminum or silicon [20] . Within the presence of an aqueous electrolyte solution, negatively charged mineral surfaces pull cations and polar water, composing a double-layer system (Fig. 4). Interference between two double layers makes a driving force that pushes the clay platelets away from each other; It additionally causes an increase in the cation concentration between the platelets and consequently, free water must be drawn into the system to reestablish balance. For example, Clay layers are negatively charged, and it prompts a repellent force between layers. However, cations near the surface of the layer counterbalance this negative charge. Replaceable cations are not too strong on the external surfaces. Consequently, they will in general diffuse from zones of high concentration towards zones of low concentration in the bulk solution. The outcome is a diffuse set of ions around a clay particle. This arrangement is called the diffuse electric double layer.

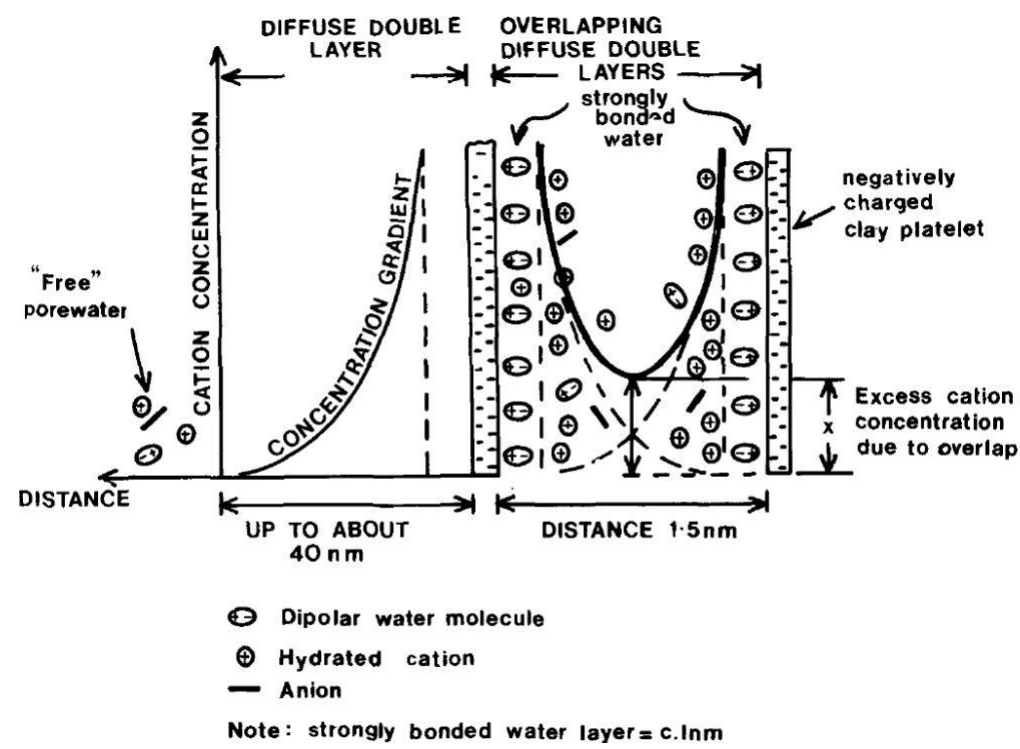

Figure 4. A double-layer osmotic swelling model of two clay mineral platelets [14]

Fig. 5 shows the diffuse double layer. It is defined as a group of negative charge set on an outer surface of clay and a cloud of positive ions placed on the outer surface. 


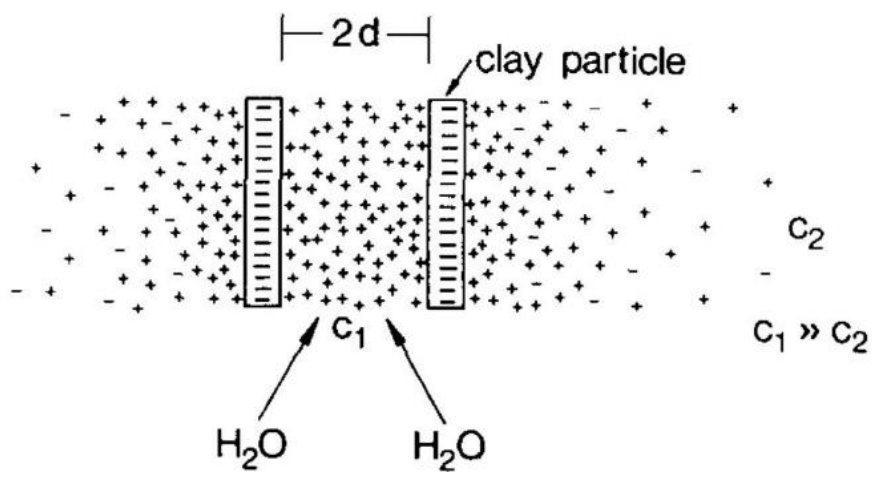

Figure 5. Diffuse double layer from [15]

To form the diffuse double layer, cations close to the surface balance the negative charge and then the exchangeable cations tend to diffuse. As a result, a repellent force appears between the two overlapping layers of the clay particles. This repellent force varies with the balance and radius of the counterions in the double layer and the concentration of electrolytes in the pore water [18].

From this literature review on the process and swelling behavior, we note that the existence of coarse materials (sand) in expansive soil has a significant effect on swelling. Whereas, Increasing the hydrophobic sand ratio reduces the hydrophilic clay ratio and thus reduces the efficacy of crystalline and osmotic swelling and improves the behavior of the expansive soil.

Knowing the swelling behavior is very important, as it enables to give a preliminary explanation about the effect of sand on the behavior of the expansive soil, but knowing the swelling behavior alone is not sufficient and it is necessary to know the effect of more than one parameter together, such as density and initial moisture with different sand ratios on the physical and mechanical properties of the expansive soil. This is will be highlighted in the following sections.

\section{Effect of sand on physical characteristics}

\subsection{Consistency (Aterberg) Limits}

There are many studies that show the positive effect of sand on the consistency of the expansive soil [7] [10] [21].

Louafi and Baher [10] conducted an experimental study to examine the effect of sand on soil consistency. Fig. 6 shows the granular gradient curves for sand and 
clay (bentonite) used in the study. the physical characteristics of bentonite are showed in Table 1.

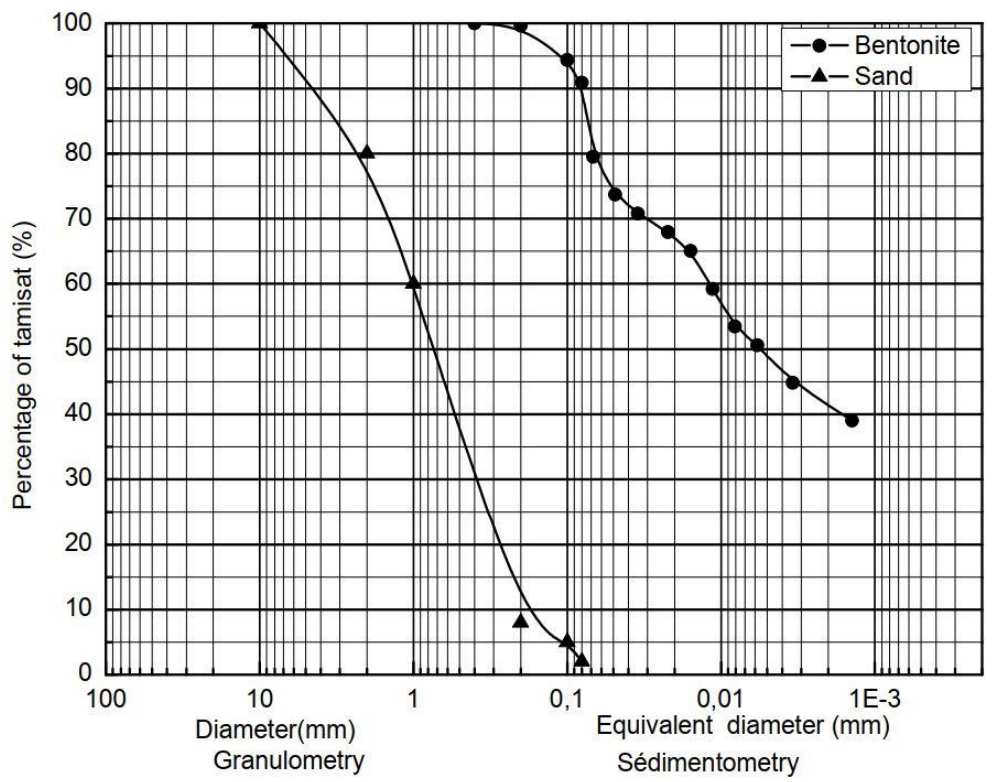

Figure 6. The granular gradient curves of sand and bentonite [10]

It is noticed from Fig. 6 that the sand used is medium poorly graded sand and the bentonite used contains in its composition $65 \%$ clay particles of less than $2 \mu \mathrm{m}$ in diameter and $10 \%$ coarse (sand) with a diameter greater than $0.075 \mathrm{~mm}(75 \mu \mathrm{m})$.

Table 1. Physical characteristics of bentonite [10]

\begin{tabular}{|c|c|}
\hline Property & Value \\
\hline Specific gravity & 2.6 \\
\hline \multicolumn{2}{|c|}{ Consistency properties } \\
\hline Liquid limit $(\%)$ & 187 \\
\hline Plastic limit $(\%)$ & 47 \\
\hline Plastic limit $(\%)$ & 140 \\
\hline Optimum moisture content $(\mathrm{OMC})(\%)$ & 25 \\
\hline Maximum dry unit weight $\left(\boldsymbol{\gamma}_{\boldsymbol{d m a x}}\right)\left(\mathrm{kN} / \mathrm{m}^{3}\right)$ & 1.6 \\
\hline
\end{tabular}

Louafi and Baher [10] conducted a series of tests to study the evolution of limits of consistency using two different diameter sizes of sand $([0.1 \mathrm{~mm}<\mathrm{d}<0.2 \mathrm{~mm}]$ 
and $[0.2 \mathrm{~mm}<\mathrm{d}<0.4 \mathrm{~mm}]$ ) to study its effect on the consistency of expansive clay soils. To do this, the soil is mixed with different percentages of sand (10-20-30-40$50-60-70 \%$ ) and then limits of consistency is defined using distilled water.

Fig. 7 and 8 show the change of both the liquid limit and the plasticity index in terms of the percentage of fine and medium sand. The results show that adding sand to clay (bentonite) considerably reduces both the liquid limit and the plasticity index. The greater decrease is for sand of larger diameters, however the difference in result between the two fine and medium sand is small. This reduction in the liquid limit and the plasticity index is explained by the decrease in the content of fines that contribute to the plasticity with the increase in the percentage of sand. Thus, the number of bonds between the clay particles decreases with the increase in the bonds of the clay-sand particles or the bonds of the sand and sand particles.

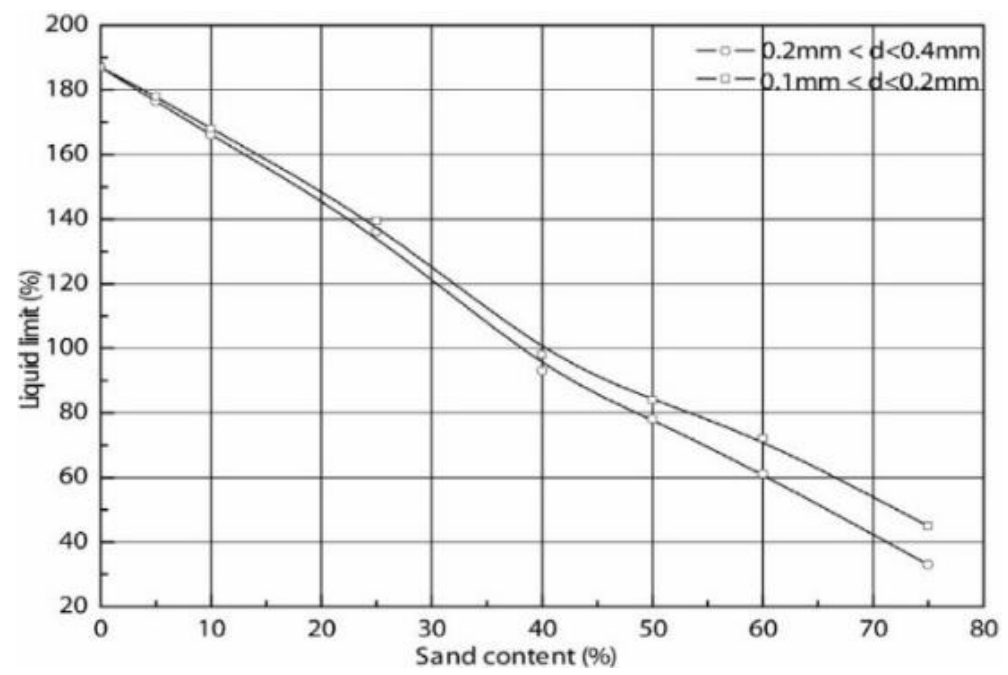

Figure 7. Change of the liquid limit in terms of the sand content [10]

As for the difference in the liquid limit and the plasticity index related to the effect of the size of the grains of added sand. This is probably due to the total specific surface area of water absorption of the sample which depends on the size of the sand grains. This specific surface is more important when the sand particles are finer, permitting the mixtures to absorb more water and consequently increasing of liquid limit.

Roy [7] also used three gradients of sand: fine, medium and coarse sand with percentages from 0 to $15 \%$ in his experimental study. It was also found that increasing the percentage of sand reduces the values of the Liquid and plastic limits, 
however, the effect of sand gradation was not clear because of the fact that the percentage of added sand is small, not more than $15 \%$ and the effect of the gradient on the consistency is small as noted in Table 2.

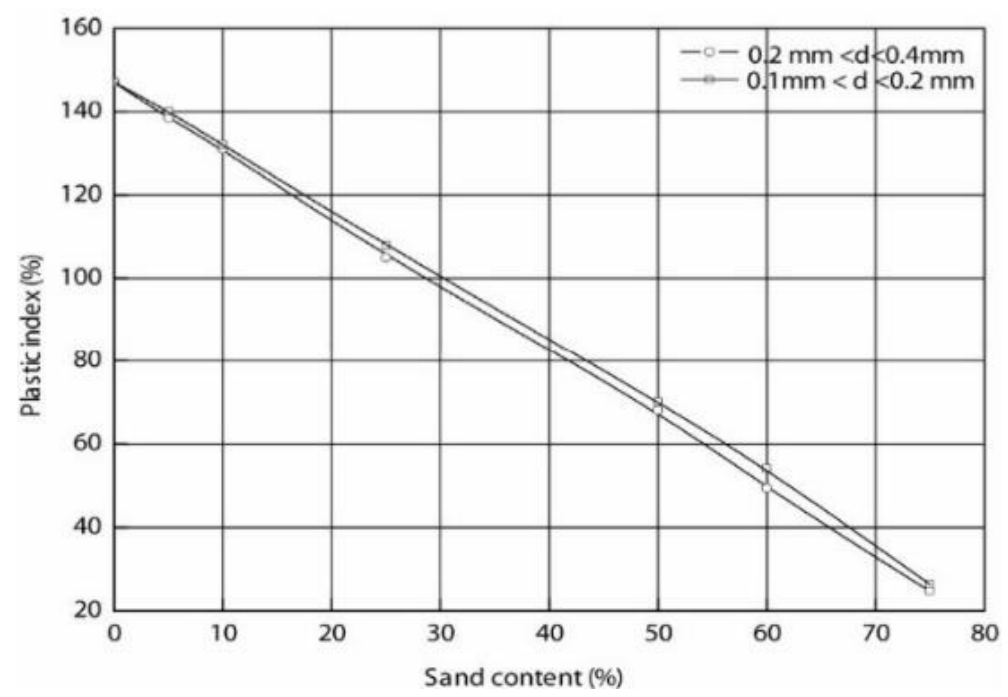

(b)

Figure 8. Change of the plastic index in terms of the sand content [10]

Table 2. LL, PL and PI of clay sand mixtures [7]

\begin{tabular}{|c|c|c|c|c|}
\hline Type of Sand Mixed & \% of Sand & LL (\%) & PL (\%) & $P I(\%)$ \\
\hline \multirow{4}{*}{ Fine Sand } & 0 & 40.00 & 24.90 & 15.10 \\
\cline { 2 - 5 } & 5 & 35.85 & 24.50 & 11.35 \\
\cline { 2 - 5 } & 10 & 35.15 & 24.35 & 10.80 \\
\cline { 2 - 5 } & 15 & 34.80 & 24.10 & 10.70 \\
\hline \multirow{4}{*}{ Medium Sand } & 0 & 40.00 & 24.90 & 15.10 \\
\cline { 2 - 5 } & 5 & 36.15 & 24.35 & 11.80 \\
\cline { 2 - 5 } & 10 & 36.00 & 24.30 & 11.70 \\
\cline { 2 - 5 } & 15 & 35.60 & 24.05 & 11.55 \\
\hline \multirow{3}{*}{ Coarse Sand } & 0 & 40.00 & 24.90 & 15.10 \\
\cline { 2 - 5 } & 5 & 36.25 & 24.30 & 11.95 \\
\cline { 2 - 5 } & 10 & 36.05 & 25.14 & 10.91 \\
\cline { 2 - 5 } & 15 & 35.85 & 24.65 & 11.20 \\
\hline
\end{tabular}


Whereas in the study of Srikanth and Mishra [22], they use fine (FS) and medium (MS) sand, but with percentages of sand of more than 50\%, and with two different types of clay (B1 low plasticity and B2 High plasticity) and they have obtained the same previous results. However, the effect of the size of the sand particles becomes more evident with an increase in the plasticity of the clay used, as shown in Fig. 9.

Regarding the shrinkage limit, Srikanth \& Mishra [22] [23] and Yang et al [24] found that the shrinkage limit increases with an increasing percentage of sand. As shown in Fig. 10, which shows the results of the shrinkage limit of fine clay-sand and medium clay-sand mixtures. For an identical clay content in the mixture, fine clay-sand mixtures showed higher shrinkage limits.

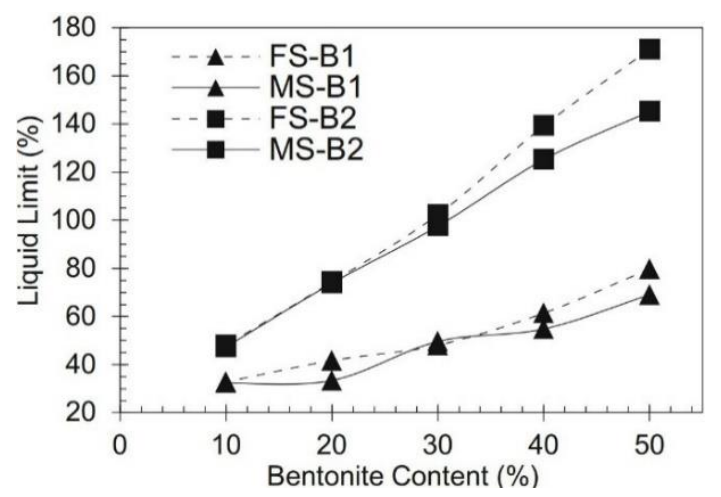

Figure 9. Variation of the liquid limit for clay-sand mixtures with fine sand and medium sand according to the content of bentonite [22]

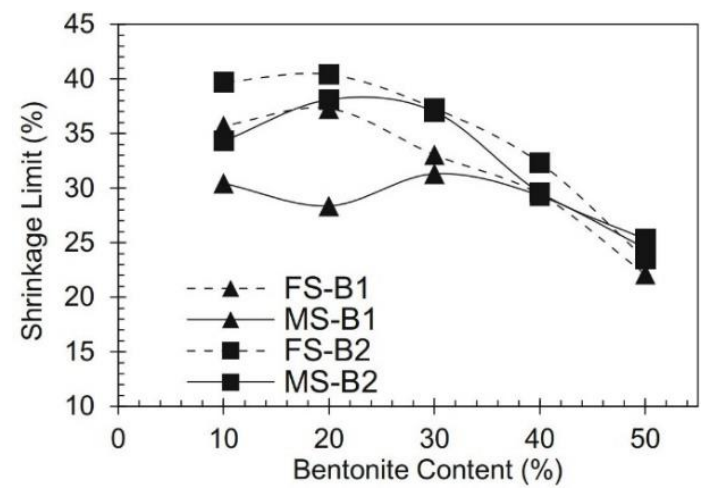

Figure 10. Variation in shrinkage limit of fine sand-clay(bentonite) and medium sand- clay mixtures with bentonite content [22] 


\subsection{Optimum moisture and maximum dry density}

Roy [7] made a visible comparison of the effects of mixing different types of sand, for instance, fine, medium, coarse and with variable proportions in soil on maximum dry density (MDD) and optimum moisture content (OMC), Fig. 11 shows the experimental results in terms of maximum dry density (MDD) and Fig. 12 shows the experimental results in terms of optimum moisture content (OMC) for various percentages of sand.

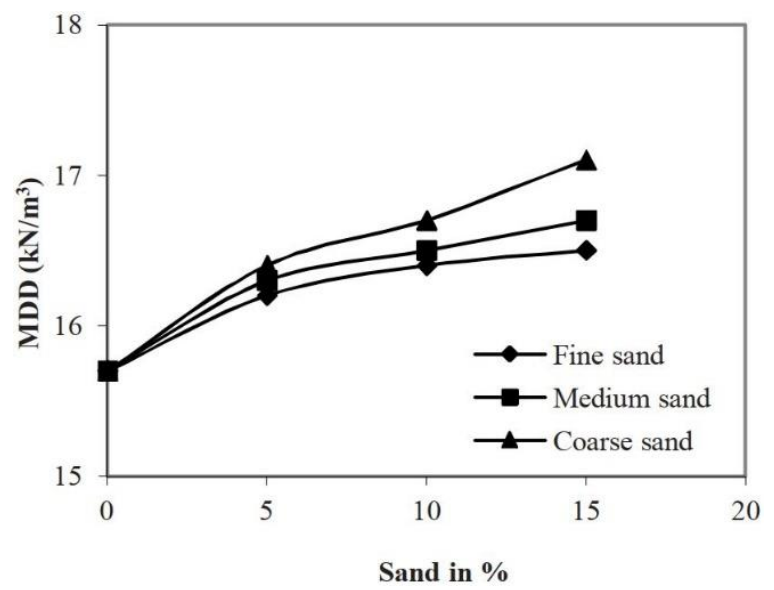

Figure 11. Variation of maximum dry density of clay-sand mixtures [7]

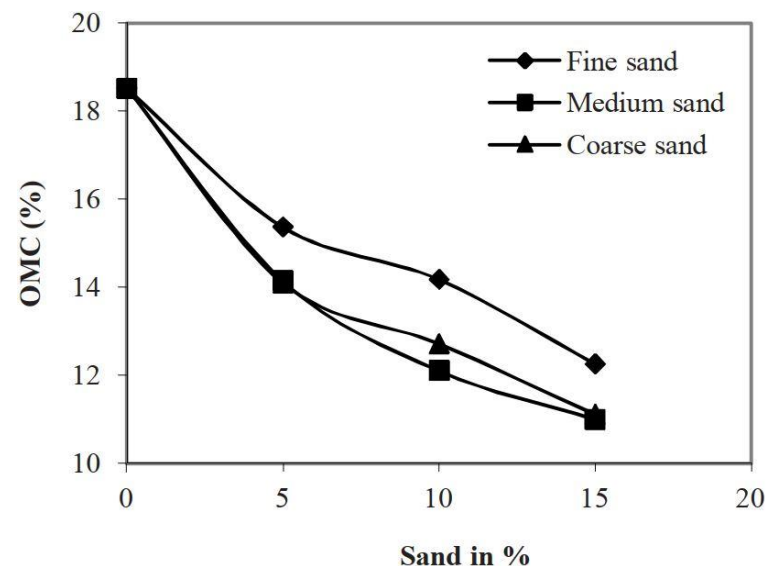

Figure 12. Variation of optimum moisture content of clay-sand mixture [7] 
From Fig.11, it is observed that when mixing expansive soil with fine sand from 0 to $15 \%$, MDD increases from $15.70 \mathrm{kN} / \mathrm{m} 3$ to $16.50 \mathrm{kN} / \mathrm{m} 3$. But for the same expansive soil when medium sand is mixed in increasing percentages, the MDD increases from $15.70 \mathrm{kN} / \mathrm{m} 3$ to $16.70 \mathrm{kN} / \mathrm{m} 3$. In the case of mixing coarse sand, the effect on MDD increases even more. Thus, increasing the size of sand grains results in an increase in the maximum dry density.

The result of mixing sand in numerous percentages on the $\mathrm{OMC}$ of expansive soils is shown in Fig. 12. It is noted that adding all kinds of sand in increasing percentages decreases progressively the OMC values compared to the tested soil and this value decreases progressively from $18.52 \%$ to $11.00 \%$ when the percentage of mediumgrained sand increases from 0 to $15 \%$. this is often a sign of reduced water demand to achieve the required compaction in the field when the percentage of sand increases in expansive soil [7].

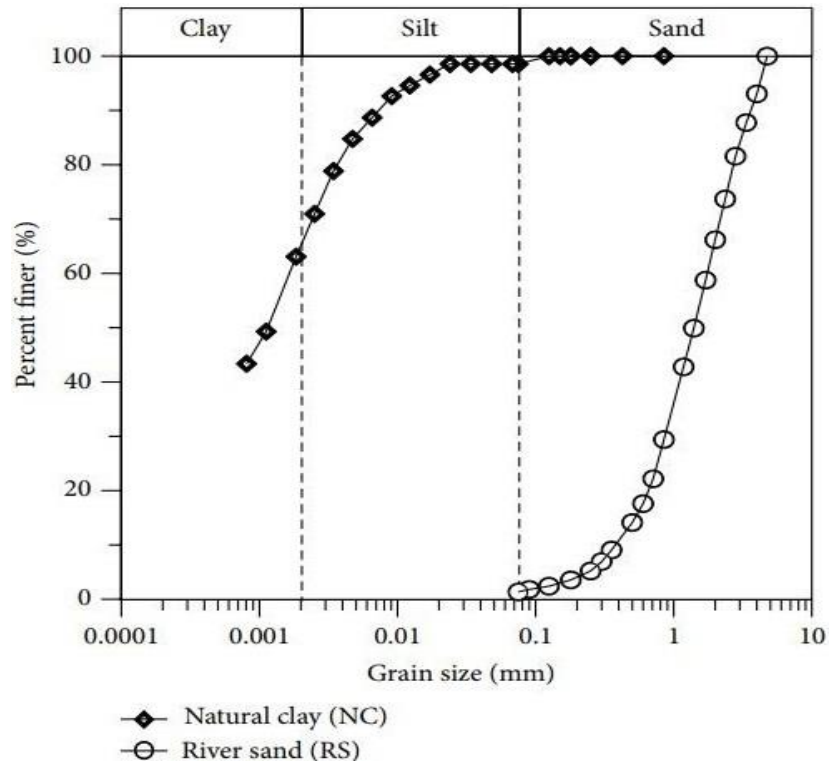

Figure 13. Grain size distribution of investigated sand and clay [25]

Khan et al [25] conducted standard proctor experiments for three clay-sand mixtures with percentages of sand of $(0-20-40) \%$ to work out the maximum dry density and optimum moisture content for each percentage of mixing. Clay-sand mixtures were prepared based on the dry weights of the materials. Fig. 13 presents the Grain size distribution of sand and clay materials. It is observed that there is a continuous increase in the maximum dry density Fig. 14-(a). The reason is Due to 
the decrease in the volume of pores in the soil and the decrease of absorption as a result to the replacement of a soft part that can hold a large amount of water with a coarse part with little ability to retain water and this is confirmed by the optimum moisture values of the mixtures wherever it is noted the optimum moisture values decrease by increasing the percentage of added sand.

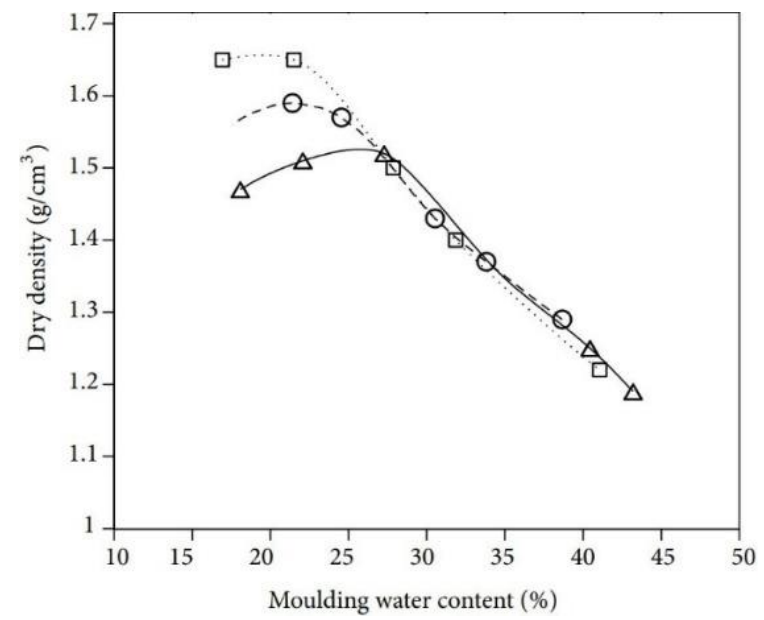

(a)

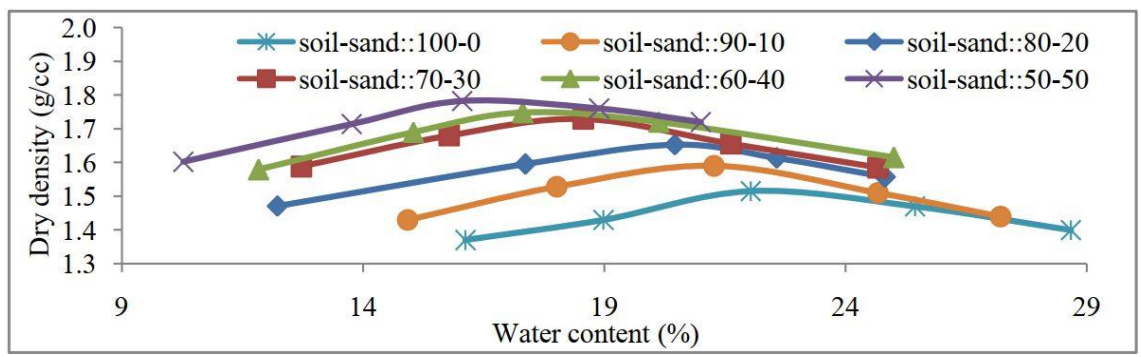

(b)

Figure 14.Compaction characteristics of clay-sand mixtures: (a) Khan et al [25] (b) Gupta and Sharma [26]

Where: NC represents the Nature clay without any added sand ( $0 \%$ of added sand); CS-I represents the clay-sand mixture with added sand of 20\%; CS-II represents the clay-sand mixture with added sand of $40 \%$.

Gupta and Sharma [26] also conjointly performed standard Proctor experiments. Fig. 13-(b) shows the curves of the water content and the dry density of the expansive soil for different percentages of sand ranging from $10 \%$ to $50 \%$. It is observed that 
the maximum dry density (MDD) of the clay-sand mixtures increases with the increase in the percentage of sand. While the opposite happens with optimum moisture content (OMC), for the same reason mentioned previously.

Srikanth and Mishra [23] conducted standard Proctor experiments on expansive soil with different percentages of sand (50-90\%) for two grain size of sand (fine sand FS and medium sand MS) and determined the optimum moisture content (OMC) and maximum dry density (MDD) for all added sand percentages as shown in Table 3.

Table 3. OMC and MDD of various sand-clay mixture [23]

\begin{tabular}{|c|c|c|c|c|}
\hline \multirow{2}{*}{$\begin{array}{c}\text { Sand: bentonite } \\
\text { proportions }\end{array}$} & \multicolumn{6}{|c|}{$\begin{array}{c}\text { Bentonite-1 (B1) } \\
(\%)\end{array}$} & $\begin{array}{c}\text { Bentonite-2 (B2) } \\
\text { Medium sand }\end{array}$ & $\begin{array}{c}\text { OMC } \\
(\%)\end{array}$ & $\begin{array}{c}\text { MDD } \\
(\mathrm{kg} / \mathrm{m} 3)\end{array}$ \\
\hline \multicolumn{5}{|c|}{ Medium sand } \\
\hline $\mathbf{5 0 : 5 0}$ & 22.5 & 1565 & 12.9 & 1598 \\
\hline $\mathbf{6 0 : 4 0}$ & 19.0 & 1628 & 11.6 & 1624 \\
\hline $\mathbf{7 0 : 3 0}$ & 16.0 & 1662 & 17.5 & 1657 \\
\hline $\mathbf{8 0 : 2 0}$ & 15.0 & 1710 & 18.5 & 1651 \\
\hline $\mathbf{9 0 : 1 0}$ & 18.5 & 1670 & 17.9 & 1611 \\
\hline \multicolumn{5}{|c|}{ Fine sand } \\
\hline $\mathbf{5 0 : 5 0}$ & 22.5 & 1585 & 20.9 & 1555 \\
\hline $\mathbf{6 0 : 4 0}$ & 20.5 & 1595 & 20.2 & 1582 \\
\hline $\mathbf{7 0 : 3 0}$ & 18.0 & 1655 & 18.8 & 1607 \\
\hline $\mathbf{8 0 : 2 0}$ & 18.4 & 1701 & 20.5 & 1612 \\
\hline $\mathbf{9 0 : 1 0}$ & 17.2 & 1641 & 22.4 & 1579 \\
\hline
\end{tabular}

The data from the standard Proctor compaction test in Table 3 shows that for the same percentage of sand, the FS-bentonite and MS-bentonite mixture showed a different value for OMC and MDD indicating the likelihood that sand particle size affected the compaction properties of the mixtures. Mixtures with MS resulted in relatively higher MDD and lower OMC values for both types of bentonite (Clay) that may be attributed to the effective filling of the clay particle within the spaces formed between the sand particles. The data in Table 3 shows that mixtures with percentage of sand of $80 \%$ exhibited the highest density among all mixtures. Once the voids formed between the individual sand particles are completely filled by clay particles, with another addition of sand more than $80 \%$, there will be voids between the grains of sand that are not filled with clay particles, but rather with water and air, i.e. the clay particles will not occupy all the spaces between the sand grains, and this 
is the reason for the decrease in MDD. Similar results have been reported by Yang et al [24], K. Raw \&G. Raw [27] and Atemimi [28].

It is obvious that sand improves the maximum dry density of expansive soils, however increasing the dry density of expansive soils as a result of increasing the percentage of sand will cause more swell pressure and swell amplitude. This calls for studying the effect of sand content in expansive soils on its mechanical characteristics.

\section{Effect of sand on mechanical characteristics}

\subsection{Swelling Potential and Swelling Pressure}

Louafi and Baher [10] studied the effect of added sand and its grain size on the swelling potential and swelling pressure by conducting free-swell experiments of different grain sizes of sand and different added sand percentages from 0 to $70 \%$ for each type of grain size. In all experiments, both the dry density of $15 \mathrm{kPa}$ and the initial moisture of $26 \%$ were fixed.

Samples were prepared at laboratory temperature by hand mixing and pressed statically into oedometric cell in three layers, each layer with a thickness of $5 \mathrm{~mm}$, to ensure homogeneous samples were obtained, using a hand press. the swell was allowable under a seating surcharge of $3 \mathrm{kPa}$ by immersion. After obtaining the final heave $(\Delta \mathrm{H})$, the sample was consolidated under increasing vertical loads until the initial thickness was reached.

The curves of Fig. 14 show that the swelling pressure and swelling potential of expansive soils decrease with an increase in the percentage of added sand. Coarse sand with a larger grain size seems to produce a greater reduction in both the swelling potential and the swelling pressure. This difference expresses the impact of sand grains on swelling. These above results can be explained by the fact that the clay content decreases by adding sand, which is usually an inert material. Indeed, increasing the percentage of sand reduces the swelling potential and swelling pressure; This is on the one hand. On the opposite hand, much of this swelling is absorbed by the voids between the sand grains. Once the sand fraction is coarser, these voids become larger. consequently, there is a decrease in the swelling potential and swelling pressure caused by soil swelling. 
A. N. Alnmr and R. P. Ray - Acta Technica Jaurinensis, Vol. 14, No. 4, pp. 521-552, 2021

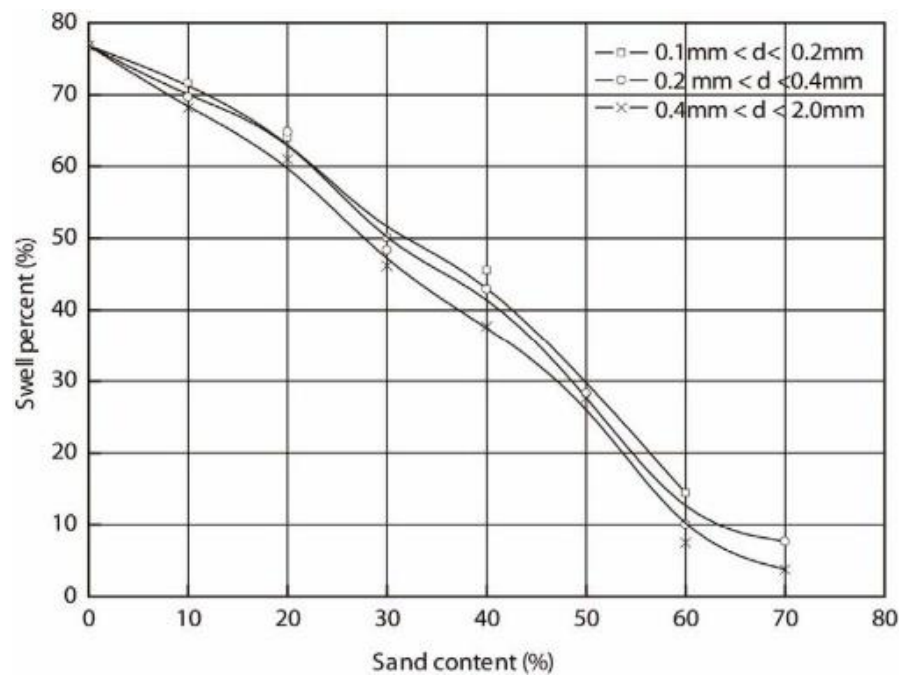

a)

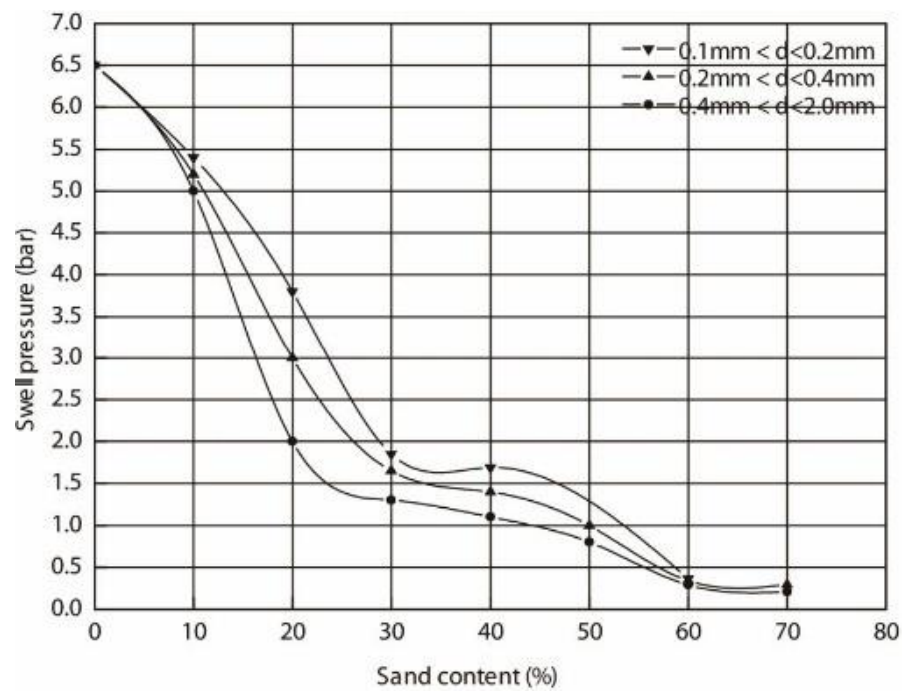

b)

Figure 15.Variation of swelling potential and swelling pressure with percentage of sand for clay-sand mixture prepared at same dry density and initial moisture [10] 
Srikanth and Mishra [23] conducted free-swell experiments by standard consolidometer according to ASTM D 2435. To highlight the importance of water content on the behavior of the mixtures, each mixture was pressed at $5 \%$ dry OMC and $5 \%$ wet $\mathrm{OMC}$.

Samples were formed with dimensions of $60 \mathrm{~mm}$ in diameter and $15 \mathrm{~mm}$ in height in a way that achieves uniformity with density and moisture. All samples were formed according to their maximum dry density, with three different initial moistures. The sample was formed in a consolidation cell with a seating pressure of $4.9 \mathrm{kPa}$, then submerged in water and left until complete swelling. Then the samples were consolidated, gradually increasing the stress from 4.9 up to $784.5 \mathrm{kPa}$.

Tables 4 and 5 show the swelling pressure and swelling potential data exhibited by various mixtures of sand and bentonite (clay). From the data shown within the tables 4 and 5, we note that the swelling pressure and swelling potential decrease with an increase in the percentage of sand no matter what the initial compression condition. The data showed that, for any given percentage of the sand in the mixture, the samples compacted on the dry side of OMC exhibited higher swelling potential followed by those compacted in OMC.

Table 4. Swelling Potential results of sand clay mixture [23]

\begin{tabular}{|c|c|c|c|}
\hline \multirow{2}{*}{$\begin{array}{c}\text { Sand-bentonite } \\
\text { proportions }\end{array}$} & \multicolumn{3}{|c|}{ Swelling potential (\%) } \\
\cline { 2 - 4 } & MDD-OMC & $\begin{array}{c}\text { MDD-5 \% } \\
\text { dry of OMC }\end{array}$ & $\begin{array}{c}\text { MDD-5 \% } \\
\text { wet of OMC }\end{array}$ \\
\hline Medium sand (MS) & 35.0 & 17.0 \\
\hline $\mathbf{5 0 : 5 0}$ & 18.7 & 8.0 & 7.8 \\
\hline $\mathbf{6 0 : 4 0}$ & 16.2 & 18.5 & 1.6 \\
\hline $\mathbf{7 0 : 3 0}$ & 4.6 & 6.3 & 0 \\
\hline $\mathbf{8 0 : 2 0}$ & 1.0 & 0 & 0 \\
\hline $\mathbf{9 0 : 1 0}$ & 0 & 24.1 & 10.2 \\
\hline Fine sand (FS) & \multicolumn{3}{|c|}{} \\
\hline $\mathbf{5 0 : 5 0}$ & 18.4 & 11.5 & 22.7 \\
\hline $\mathbf{6 0 : 4 0}$ & 13.3 & 5.2 & 1.1 \\
\hline $\mathbf{7 0 : 3 0}$ & 2.0 & 7.4 & 0.2 \\
\hline $\mathbf{8 0 : 2 0}$ & 1.4 & 0.2 & \\
\hline $\mathbf{9 0 : 1 0}$ & 0.2 & &
\end{tabular}

It was also found from tables 4 and 5 that sand with FS exhibits relatively higher swelling pressure and swelling potential for any given percentage of the sand in the mixture. Regardless of the size of the sand grains, mixtures containing bentonite less 
than $20 \%$ showed a general decrease in the observed swelling. Whereas, the mixture with high bentonite contents (i.e. 50 and $40 \%$ ) showed very high values of swelling pressure and swelling potential. Comparison of the mixtures shows that for the same percentage of sand and bentonite, the bentonite containing FS showed a higher value for swelling potential and swelling pressure compared to the bentonite with MS. Bentonite effectively fills the smaller spaces between individual FS particles compared to the relatively larger void spaces between MS particles. Once the spaces between the FS particles are filled in with the clay, along with a further increase in the volume of the clay, it will begin pushing out the sand particles leading to a higher value for swelling potential and swelling pressure [23]

Table 5. Swelling Pressure results of sand clay mixture [23]

\begin{tabular}{|c|c|c|c|}
\hline \multirow{2}{*}{$\begin{array}{c}\text { Sand-bentonite } \\
\text { proportions }\end{array}$} & \multicolumn{3}{|c|}{ Swelling pressure (kPa) } \\
\cline { 2 - 4 } & MDD-OMC & $\begin{array}{c}\text { MDD-5 \% } \\
\text { dry of OMC }\end{array}$ & $\begin{array}{c}\text { MDD-5 \% } \\
\text { wet of OMC }\end{array}$ \\
\hline Medium sand (MS) & 388.4 & 335.3 \\
\hline $\mathbf{5 0 : 5 0}$ & 340.5 & 219.1 & 242.2 \\
\hline $\mathbf{6 0 : 4 0}$ & 300.1 & 215.8 & 50.4 \\
\hline $\mathbf{7 0 : 3 0}$ & 134.4 & 79.7 & 21.1 \\
\hline $\mathbf{8 0 : 2 0}$ & 23.5 & 0 & 0 \\
\hline $\mathbf{9 0 : 1 0}$ & 10.2 & 431.7 & 343.3 \\
\hline Fine sand (FS) & \multicolumn{3}{|c|}{} \\
\hline $\mathbf{5 0 : 5 0}$ & 372.2 & 258.9 & 332.3 \\
\hline $\mathbf{6 0 : 4 0}$ & 344.4 & 101.0 & 71.5 \\
\hline $\mathbf{7 0 : 3 0}$ & 79.5 & 94.7 & 21.6 \\
\hline $\mathbf{8 0 : 2 0}$ & 52.6 & 10.1 & 5.0 \\
\hline $\mathbf{9 0 : 1 0}$ & 7.8 &
\end{tabular}

Phanikumar et al [9] conducted one-dimensional swell-consolidation tests, in order to study the swelling pressure and potential swelling of clay-sand mixtures. The dry density $\left(\gamma_{\mathrm{d}}\right)$ and initial water content $\left(\mathrm{w}_{\mathrm{i}}\right)$ of the samples were fixed at $12 \mathrm{kN} / \mathrm{m} 3$ and $0 \%$, respectively.

Clay-sand mixtures were thoroughly mixed with a spatula and statically compacted into the consolidometer ring (diameter $60 \mathrm{~mm}$, thickness $20 \mathrm{~mm}$ ) in four layers of $5 \mathrm{~mm}$ thick each. An initial token surcharge of $5 \mathrm{kPa}$ has been applied. Samples were allowed to undergo free swelling by immersion until the swelling had stabilized. To assess the equilibrium heave $(\Delta \mathrm{H}), \Delta \mathrm{H}$ (Y axis), and log time in 
minutes (X-axis) plots were made and when the curves became a straight line, equilibrium heave was understood to have been reached Fig. 15.

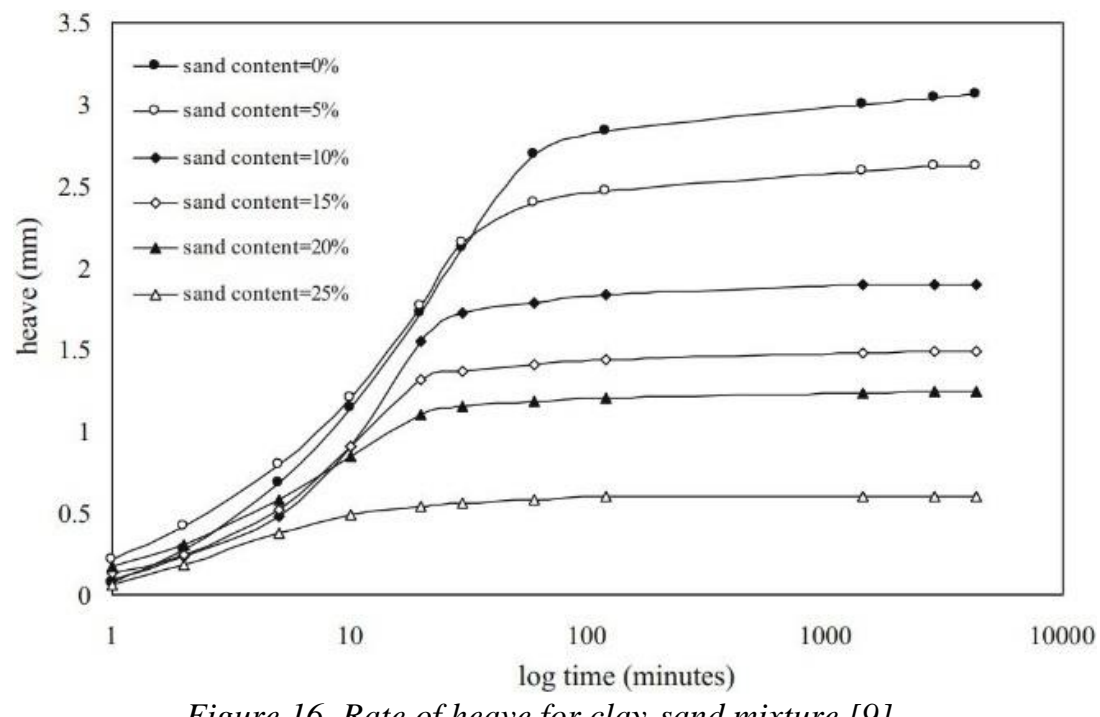

Figure 16. Rate of heave for clay-sand mixture [9]

Fig. 15 shows the heave ratio of clay-sand mixtures having completely different sand percentages. The equilibrium for all mixtures was obtained at the end of 3 days or 4,320 minutes of immersion besides that the equilibrium time becomes shorter as the percentage of sand in the mixture increases. The height of the unmixed clay sample ( $0 \%$ fine sand content) was the highest at $3 \mathrm{~mm}$, giving a swelling potential of $15 \%$. Heave decreases as the percentage of fine sand in the mixture increases. It reaches $0.60 \mathrm{~mm}$ at a percentage of sand of $25 \%$ which corresponds to the swelling potential (S\%) $3 \%$.

Fig. 16 shows the change of swelling potential with an increase in the percentage of sand. A noticeable decrease in swelling potential with increasing sand percentage is observed. Swelling potential (S\%) decreases from 15 to 3\% at 25\% sand content [9]. 


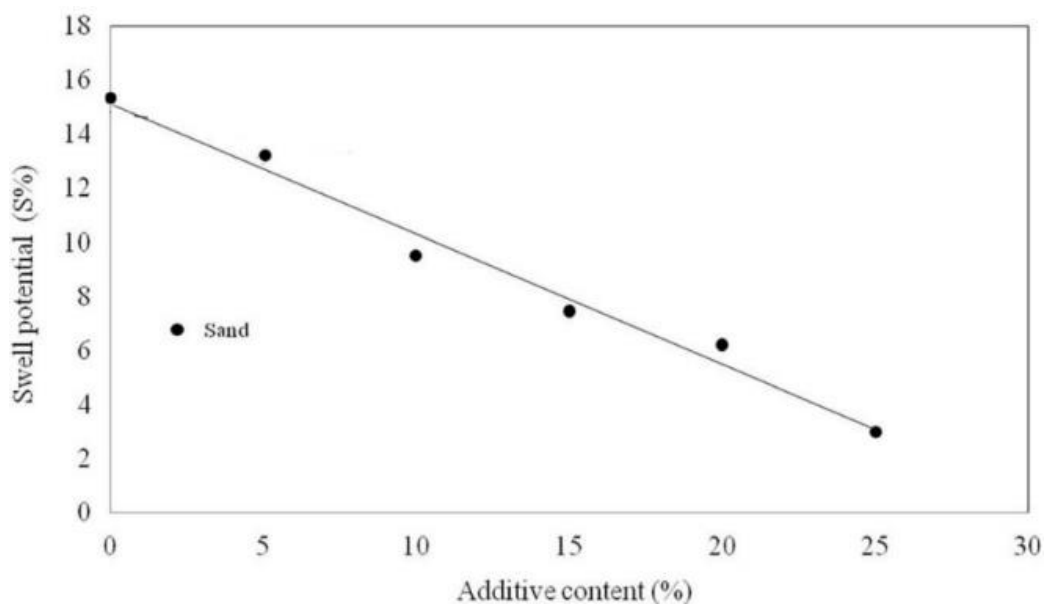

Figure 17. Changing of swell potential with Percentage of sand [9]

Fig. 17 shows the variation of the swell pressure $(\mathrm{kPa})$ as the percentage of sand in the mixture increases. The swelling pressure decreased from 350 to $54 \mathrm{kPa}$ once the percentage of sand in the mixture increased from 0 to $25 \%$. Because the nonexpansive material such as sand replaces the expansive clay material in the mixture, the swelling potential decreases, and therefore the swelling pressure also decreases [9].

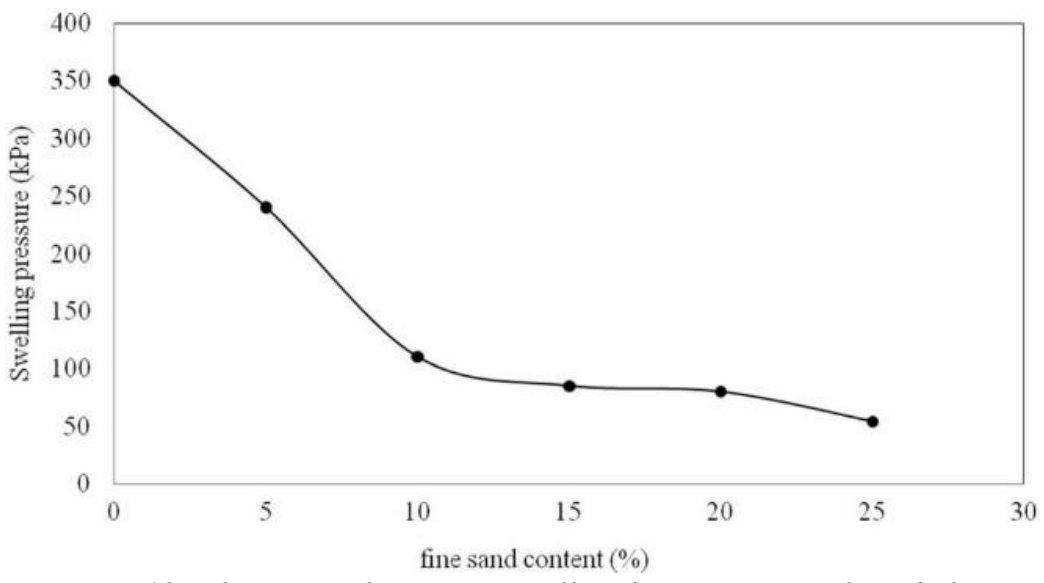

Figure 18. Changing of pressure swell with Percentage of sand [9]

It is evident from previous studies on the swelling potential and swelling pressure [9] [10] [23] [28] [27] [29] [24] that increasing sand in expansive soils improves both of swelling potential and swelling pressure, but most of studies are conducted 
on one density and moisture for all percentages of added sand. However, it is better to take more than one density and moisture for each added sand ratio separately, in order to better study the effect of the initial density and the initial moisture and achieve a more comprehensive understanding of the effect of the percentage of sand in the mixture especially the increase in the percentage of sand in the expansive soil causes an increase in its dry density, as indicated by the results of compaction tests.

\subsection{Strength characteristics}

Khan et al [25] performed unconfined compressive experiments of cohesive soils according to the ASTM Standard Test method (D2166-13). Samples $50 \mathrm{~mm}$ in diameter and $110 \mathrm{~mm}$ in height were used. The height-to-diameter ratio is equal to 2.2 and it falls within the range (2.0 to 2.5) specified by the ASTM standard. The strain was applied at a rate of $0.5 \mathrm{~mm} / \mathrm{min}$ and the test was stopped when the load decreased with increased strain or until $15 \%$ strain was reached.

Fig. 18 displays the compressive strength (half the peak axial pressure) according to the dry density (Fig. 19 (a)) and water content (Fig. 19 (b)). The compressive strength increases with the increase in the dry density of each material. NC (natural clay) shows the highest increase in compressive strength followed by CS-I (20\% sand content) and CS-II (40\% sand content). In contrast, an increase in water content shows a reverse trend. NC shows the highest increase in compressive strength followed by CS-I and then CS-II with a decrease in water content [25].

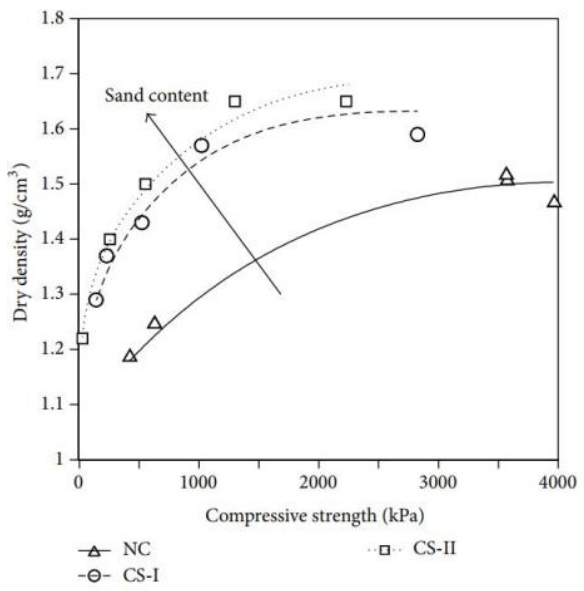

(a)

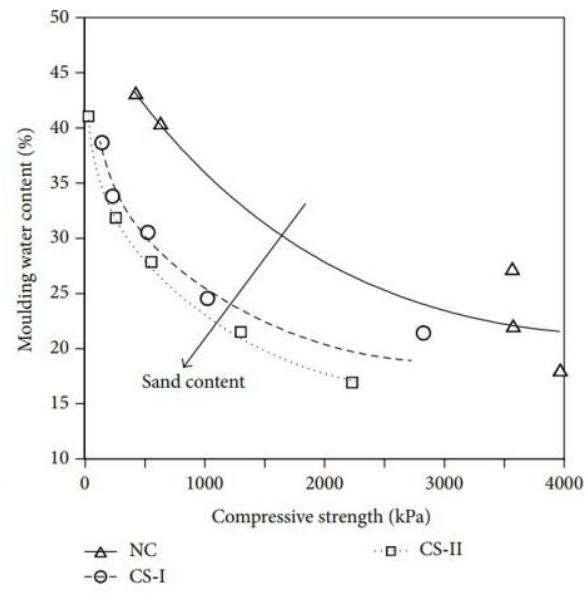

(b)

Figure 19. Compressive strength versus dry density and water content according to sand content [25] 
Despite the lowest maximum dry density of the clay, however, it showed the highest compressive strength. The higher degree of heterogeneity within the claysand mixture compared to the clay resulted in lower strength values as a result of the failure plane had to pass through the weakest zone within the sample [30].

Unconfined compression tests were also performed on statically reconstituted samples according to IS: 2720-part 10 by Nagaraj [8]. Cylindrical specimens were $76 \mathrm{~mm}$ high and $38 \mathrm{~mm}$ in diameter, and therefore have a height to diameter ratio of 2. Samples were prepared using a static compactor at the optimum moisture for each obtained from the proctor test. All samples were sheared at a strain rate of $0.25 \mathrm{~mm} / \mathrm{min}$.

Fig. 19 is a plot of unconfined compression strength versus the percentage of sand for clay-sand series. It can be seen from the Fig. 20 that, in general, there is an increase in the strength of unconfined compression with an increase in the percentage of sand up to 40 or $50 \%$, and an extra increase in the percentage of sand resulted in a decrease in strength. Once the percentage of fine particles (i.e. clay) is more, coarse particles (i.e. sand) float within the fine particle matrix, and thus, fines dominate the mechanical behavior of the clay-sand mixture. Sand gradation has shown a significant influence on the strength of the clay-sand mixture in any percentage of sand. Clay-medium sand mixtures have shown to have the maximum strength, followed by clay-fine sand and clay-coarse sand mixtures [8]. 


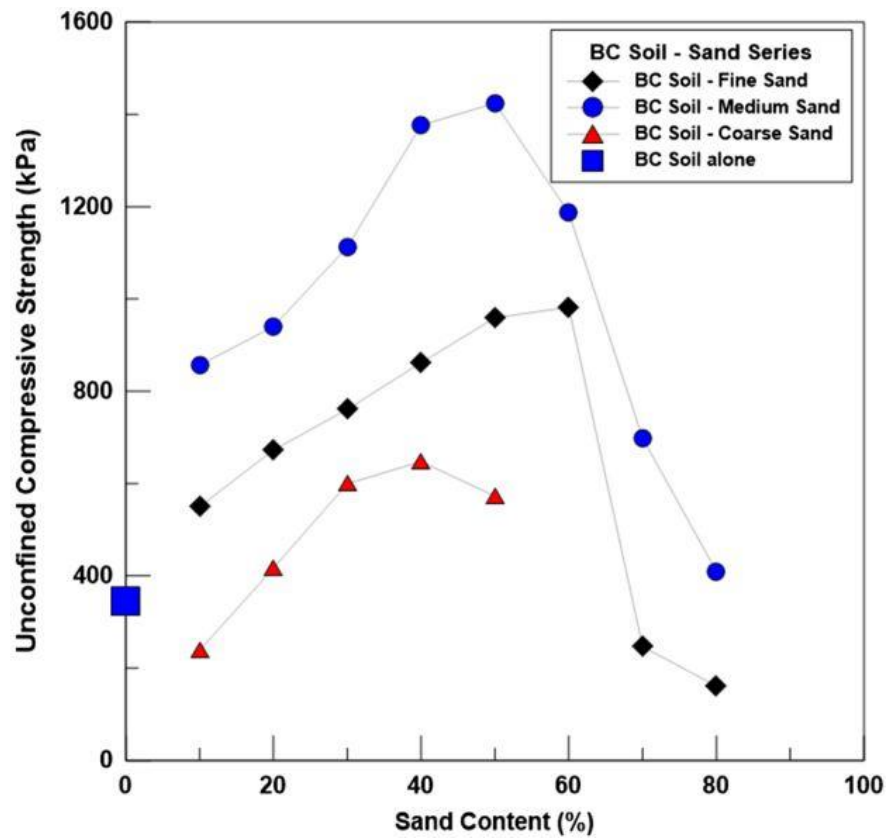

Figure 20. Unconfined compression strength versus percentage of sand with different graded sand [8]

Nagaraj [8] did not mention in his paper the dry density values of the mixtures that he worked on in the study of their strength. Whether as he adopts a constant dry density for all mixtures, or he adopts the maximum dry density corresponding to each mixture which is more likely. Also, its result is opposite to that reached by Khan et al [25], as in Khan's study, the unconfined resistance decreases with an increase in the percentage of sand up to $40 \%$, while it increases in Nagaraj [8] study. Although the Nagaraj result is more logical, as Khan [25] mentioned the presence of heterogeneity sometimes in the mixtures in his research besides that he used only three percentages of sand $(0-20-40) \%$, with a big difference between three percentages. This calls for a more comprehensive study of the effect of moisture and density with the proportion of sand in expansive soils for a more comprehensive understanding of the behavior.

The effect of sand at percentages of $0-10-20-30-40-50 \%$ on the strength of expansive soil was studied by Yang et al [24]. The samples were formed according to the maximum dry density and optimum moisture. And Yang et al [24] reached a conclusion that increasing the percentage of sand leads to a decrease in the unconfined compression strength and cohesion, and the sand percentage has a slight 
effect on the angle of internal friction. However, the expansive soil that he used contains in its composition a high percentage of sand, about $27 \%$, and thus the results that Yang et al [24] reached do not show the effect of sand on strength at low percentages within the composition of the expansive soil.

Unconfined compression tests also conducted by K. Raw \& G. Raw [27] on soil samples compacted at optimum moisture and maximum dry density to determine the unconfined compression strength (UCS). Two types of expansive soils were used: Soil-A and Soil-B. Soil-A and Soil-B have in their composition about $15 \%$ and $3 \%$ sand, respectively. Soil-B has higher plasticity compared to Soil-A.

K. Raw \& G. Raw [27] used in their study four percentages of added sand (Coarse Fraction) 0-25- 40-70\%. Fig. 20 shows the variance of unconfined compression strength with sand for two soils. Unconfined compression strength for two soils were 140.06 and $83.39 \mathrm{kPa}$. From the Fig. 20 it can be seen that unconfined compression strength decreases with the increasing percentage of sand for both soils. However, there is a relatively steep drop in strength up to a certain percentage of sand equal to about $25 \%$ for soil-A and $40 \%$ for soil-B. Percentage of sand greater than $40 \%$ has a little effect on unconfined strength in both soils. This study also used only four percentages of sand with a big difference between each percentage and the next. Therefore, the results do not exhibit the effect of low percentages of sand on unconfined compression strength.

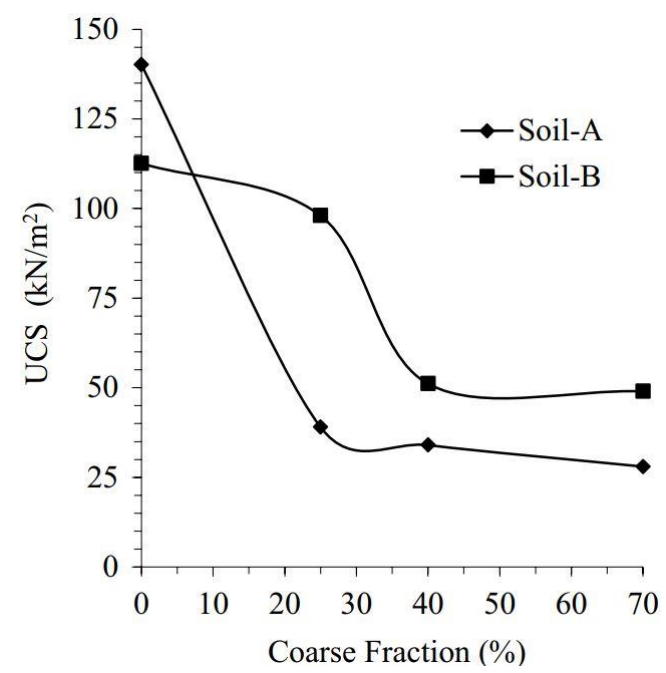

Figure 21. Variation of unconfined compression strength (UCS) with sand (coarse fraction) [27] 
Roy [7] has determined soil strength characteristics in terms of CBR with added sand in varying percentages $(0-5-10-15) \%$, and CBR tests were performed in a nonsubmerged condition in OMC (optimum moisture content) consistent with IS 2720 (part) and the result is presented in Fig. 21.

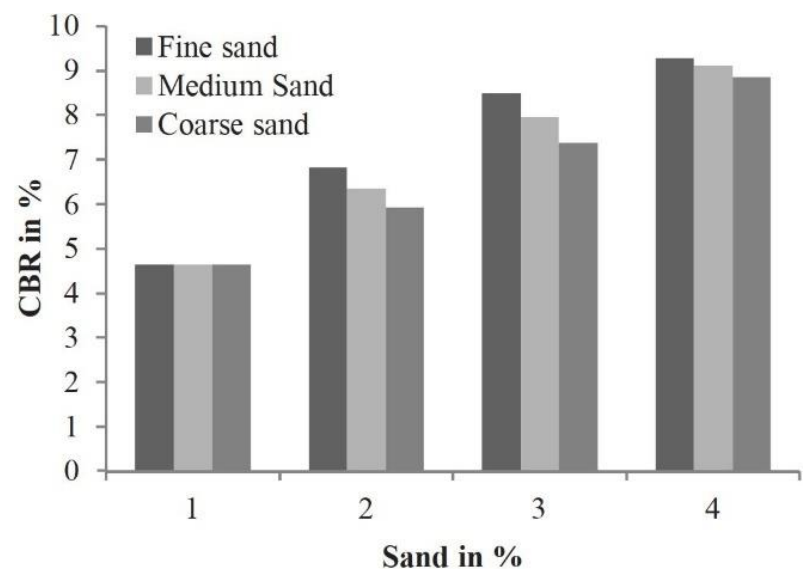

Figure 22. Variation of CBR (Unsoaked) with variable percentage of different sand [7]

Fig. 21 clarifies that the CBR value of the tested soil without any added sand in unsoaked condition is $4.65 \%$. But for mixing different types of sand with their increased percentage, this value has been amended to much higher values. It has additionally been observed that the addition of fine sand offers the best strength, whereas coarse sand offers the lowest strength. For fine sand, the CBR value increases from $4.65 \%$ to $9.28 \%$ when the percentage of sand increases from 0 to $15 \%$. This improvement might be caused by achieving better grain size distribution for the soil mixture sample. an identical trend was additionally reported by Ravi Shankar [21] and Yang et al [24].

\section{Discussion}

The results obtained from the review demonstrated that Sand is an effective solution to overcome the problems resulting from the expansive soil such as low strength and big swell amplitude and swell pressure, as it is improved the behavior of expansive soil noticeably. Increasing the hydrophobic sand ratio reduces the hydrophilic clay ratio and thus reduces the efficacy of crystalline and osmotic swelling and improves the behavior of the expansive soil. and this improvement becomes best when the percentage of sand in the expansive soil exceeds $20 \%$ as the 
absorption forces after this percentage are reduced greatly, and this is due to improving the behavior of expansive soil.

Different results have been observed in the reference studies, and sometimes the results are contradictory. The reason is the heterogeneity in the tested samples, Insufficient percentage of sand used to illustrate the behavior, or the lack of clarification of the densities and moistures that were worked on, this is a must, given the great importance of their influence on the behavior.

Finally, although most studies have shown the good effect of sand on the behavior of expansive soils, more comprehensive studies of the parameters should be worked on to clarify a comprehensive behavior of the expansive soil according to the percentage of sand.

\section{Conclusions}

The aim of this paper is to conduct an overview of the effect of sand on the behavior of expansive soils, and the results can be summarized as follows:

1. The swelling behavior of clay-sand mixtures is caused by two important mechanisms known as crystalline swelling that relates to the degree of hydration and osmotic swelling is related to the cation in the interlayers.

2. The results got showed the viability of sand in the stabilization of expansive soils and improvement of its behavior.

3. The addition of sand decreases all Atterberg limits. Except for the shrinkage limit. The decrease is slightly affected by the grain size of sand.

4. In compaction characteristics (Proctor tests), Maximum dry density (MDD) values show a significant increase with the addition of any types of sands utilized. On the other hand, OMC values show a gradual decrease with an increase in the values of sand percentages added, independent of the sand utilized.

5. Heave $(\mathrm{mm})$, swell potential $(\mathrm{S} \%)$ and swelling pressure $(\mathrm{ps})$ decreased significantly with an increase in the percentage of sand in the mixtures. The rate of heave of the mixtures as well decreased with an increase in the percentage of sand in the mixtures.

6. The unconfined compressive strength will increase with a rise in density. Conversely, the compressive strength decreases with a rise in water content of the fabric.

7. Use of fine or medium sand fractions is additionally useful to enhance the undrained strength of clay-sand mixtures.

8. The CBR values are shown a significant amount with addition of any type of sand. Anyway, a better outcome is noticed for mixing of fine sand, so an increase of the percentage of sand in expansive soil might be distinguished as cost- 
effective due to reducing the thickness of various layers of flexible pavement because of better improvement in the CBR value.

\section{Suggestions for future researches}

This research has presented the groundwork for the effecting of sand on the physical and mechanical properties of expansive soil. There is much work that remains to be completed to gain a complete understanding of the effect of sand on the behavior of the expansive soil. Due to the large number of parameters affecting the behavior of the expansive soil, which must be carefully and systematically studied. There are a number of research works that can be presented as suggested below.

1. In recent years, most of the studies were done with expansive soil without separating the sand existing within, and therefore the studies did not take the true percentage of sand on the behavior. One of the aspects to consider for further work is separating the sand from the expansive soil and then adding the desired percentage of sand precisely.

2. It would also be interesting to use more than one initial density and initial moisture for each percentage of added sand to study its effect on behavior.

3. Another aspect to consider in future work is to adopt enough percentages of added sand. It is advised to adopt the following percentages: 0-10-20-30-40-50\% at the beginning and increase them if needed.

\section{References}

[1] L.D. Jones, I. Jefferson. Expansive soils: In: Burland, J., (ed.) ICE manual of geotechnical engineering. Volume 1, Geotechnical engineering principles, problematic soils and site investigation ICE Publishing, London, UK, 2012, pp. 413-441.

URL http://nora.nerc.ac.uk/id/eprint/17002

[2] A. Aqeel, Investigation of expansive soils in Obhor Sabkha, Jeddah-Saudi Arabia, Arabian Journal of Geosciences 9 (4) (2016) pp. 1-14.

doi: https://doi.org/10.1007/s12517-016-2341-x

[3] L. Chen, X. Zhao, L. Lu, The impact of initial placement conditions on the shear strength of expansive soil, Journal of Computational and Theoretical Nanoscience 13 (4) (2016) pp. 2419-2425. doi: https://doi.org/10.1166/jctn.2016.4596 
[4] A.R. Goodarzi, H.R. Akbari, M. Salimi, Enhanced stabilization of highly expansive clays by mixing cement and silica fume, Applied Clay Science 132-133 (2016) pp. 675-684.

doi: https://doi.org/10.1016/j.clay.2016.08.023

[5] J. Nelson, D.J. Miller, Expansive soils: problems and practice in foundation and pavement engineering, John Wiley \& Sons,1997. URL http://nora.nerc.ac.uk/id/eprint/17002

[6] M. Fuchs, Development of the classification of high swelling clay content soils of Hungary based on diagnostic approach, Ph.D. thesis, Szent István University, Hungary, Gödöllö, 2012.

URL

http://archivum.szie.hu/JaDoX_Portlets/documents/docume nt_13382_section_13836.pdf

[7] T.K. Roy, Influence of sand on strength characteristics of cohesive soil for using as subgrade of road, Procedia-Social and Behavioral Sciences 104 (2013) pp. 218-224.

doi: https://doi.org/10.1016/j.sbspro.2013.11.114

[8] H.B. Nagaraj, Influence of gradation and proportion of sand on stressstrain behavior of clay-sand mixtures, International Journal of GeoEngineering 7 (1) (2016) pp. 1-10.

doi: https://doi.org/10.1186/s40703-016-0033-8

[9] B.R. Phanikumar, S. Dembla, A. Yatindra, Swelling Behaviour of an Expansive Clay Blended With Fine Sand and Fly Ash, Geotechnical and Geological Engineering 39 (1) (2021) pp. 583-591. doi: https://doi.org/10.1007/s10706-020-01480-6

[10]L. Bahia, B. Ramdane, Sand: an additive for stabilzation of swelling clay soils, International Journal of Geosciences 3 (4) (2012) pp. 719-725. doi: https://doi.org/10.4236/ijg.2012.34072

[11] Y. Deng, Z. Wu et al., Sand fraction effect on hydro-mechanical behavior of sand-clay mixture, Applied Clay Science 135 (2017) pp. 355-361. doi: https://doi.org/10.1016/j.clay.2016.10.017 
[12] M. D. Foster, The Relation Between Composition and Swelling in Clays, Clays and Clay Minerals 3 (1) (1954) pp. 205-220.

doi: https://doi.org/10.1346/ccmn.1954.0030117

[13] H. Komine, N. Ogata, Prediction for swelling characteristics of compacted bentonite, Canadian Geotechnical Journal 33 (1) (1996) pp. $11-22$.

doi: https://doi.org/10.1139/t96-021

[14] R.K. Taylor, T.J. Smith, The engineering geology of clay minerals: swelling, shrinking and mudrock breakdown, Clay Minerals 21 (3) (1986) pp. 235-260.

doi: https://doi.org/10.1180/claymin.1986.021.3.01

[15]F.T. Madsen, M. Müller-Vonmoos, The swelling behavior of clay, Applied Clay Science 4 (2) (1989) pp.143-156.

doi: https://doi.org/10.1016/0169-1317(89)90005-7

[16] L. David Suits, T. Sheahan, W. Likos, Measurement of Crystalline Swelling in Expansive Clay, Geotechnical Testing Journal 27 (6) (2004) pp. 540-546.

doi: https://doi.org/10.1520/GTJ11857

[17]E.I. Stavridakis, A solution to the problem of predicting the suitability of silty-clayey materials for cement-stabilization, Geotechnical \& Geological Engineering 24 (2) (2006) pp. 379-398.

doi: https://doi.org/10.1007/s10706-004-7934-6

[18] L. Liu, I. Neretnieks, Interaction between colloidal particles. Literature review. SKB Technical Report TR-10-26, Stockholm, Sweden, 2010 [cited 2021-05-01].

URL

https://inis.iaea.org/Collection/NCLCollectionStore/_Pu blic/41/103/41103173.pdf?r=1

[19] R.N. Yong, Soil suction and soil-water potentials in swelling clays in engineered clay barriers, Engineering geology 54 (1-2) (1999) pp. 3-13. doi: https://doi.org/10.1016/S0013-7952(99)00056-3 
[20] J.A. Greathouse, S.E. Feller, D.A. McQuarrie, The modified GouyChapman theory: comparisons between electrical double layer models of clay swelling, Langmuir 10 (7) (1994) pp. 2125-2130. doi: https://doi.org/10.1021/1a00019a018

[21] A.U. Shankar, A. Chandrasekhar, P.H. Bhat, Experimental investigations on lithomargic clay stabilized with sand and coir, Indian Highways 40 (2) (2012) pp. 21-31.

[22] V. Srikanth, A.K. Mishra, Atterberg limits of sand-bentonite mixes and the influence of sand composition, Geotechnical Characterisation and Geoenvironmental Engineering 16 (2019) pp. 139-145.

doi: https://doi.org/10.1007/978-981-13-0899-4_17

[23] V. Srikanth, A.K. Mishra, A laboratory study on the geotechnical characteristics of sand-bentonite mixtures and the role of particle size of sand, International Journal of Geosynthetics and Ground Engineering 2 (1) (2016) pp. 1-10.

doi: https://doi.org10.1007/s40891-015-0043-1

[24] J. Yang, X. Li et al., Expansive soil improvement with weathered sand, in ICTE 2013 - Proceedings of the 4th International Conference on Transportation Engineering (2013) pp. 2082-2087. doi: https://doi.org/10.1061/9780784413159.303

[25]F.S. Khan, S. Azam et al., Compressive strength of compacted clay-sand mixes, Advances in Materials Science and Engineering (2014) pp. 1-6. doi: https://doi.org/10.1155/2014/921815

[26]C. Gupta, R.K. Sharma, Influence of marble dust, fly ash and beas sand on sub grade characteristics of expansive soil, Journal of Mechanical and Civil Engineering 13 (2014) pp. 13-18.

[27] K. Mallikarjuna Rao, G.V.R. Subba Rao, Influence of Coarse Fraction on Characteristics of Expansive Soil-Sand Mixtures, International Journal of Geosynthetics and Ground Engineering 4 (19) (2018) pp. 1-7. doi: https://doi.org/10.1007/s40891-018-0136-8

[28] Y.K. Atemimi, Effect of the grain size of sand on expansive soil, Key Engineering Materials 857 (2020) pp. 367-373. 
A. N. Alnmr and R. P. Ray - Acta Technica Jaurinensis, Vol. 14, No. 4, pp. 521-552, 2021

doi:

https://doi.org/10.4028/WWW.scientific.net/KEM.857.367

[29] S.B. Ikizler, M. Aytekin, M. Vekli, Reductions in swelling pressure of expansive soil stabilized using EPS geofoam and sand, Geosynthetics International 16 (3) (2009) pp. 216-221.

doi: https://doi.org/10.1680/gein.2009.16.3.216

[30] C.E. Mullins, K.P. Panayiotopoulos, The strength of unsaturated mixtures of sand and kaolin and the concept of effective stress, Journal of Soil Science 35 (3) (1984) pp. 459-468.

doi: https://doi.org/10.1111/j.1365-2389.1984.tb00303.x 